\title{
Sunlight as a Migraine Trigger - Guilty or an Innocent Bystander?
}

\author{
Nitin K. Sethi \\ Department of Neurology, New York-Presbyterian Hospital, Weill Cornell Medical Center, New York, N.Y., USA
}

Dear Editor,

I read with interest the paper of Tekatas et al. [1] reporting 16 patients whose migraine headaches were triggered specifically by sunlight. Whether these patients represent a unique subtype of migraine is debatable. Patients with migraines frequently report bright or flickering light as a trigger for their headache. That said, when many of these patients were exposed to bright or flickering light in a controlled fashion, it failed to launch a migraine attack in the vast majority of them $[2,3]$. In my personal experience as a neurologist, who also suffers from migraines, it is the context of the trigger which is more important than the trigger itself. Exposure to bright light or sunlight is more likely to trigger my migraine attack if I am sleep-deprived, dehy- drated, working under stress, have missed my breakfast or had a glass of wine the evening before. Patients frequently fail to associate the preceding circumstances (the context surrounding the trigger) and only report bright light or exposure to sunlight as their migraine launcher. This may also explain why their migraine is not consistently triggered by each and every exposure to bright sunlight. For a migraine attack to occur, a perfect storm has to brew first which requires the coming together of many endogenous (hormonal levels, sleep quality the night before) and exogenous (preceding intake of alcohol, level of hydration, stress level) factors. Sunlight or for that matter any bright or flickering light is just the final trigger in this whole cascade.

\section{References}

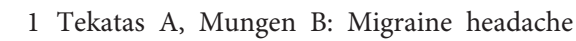
triggered specifically by sunlight: report of 16 cases. Eur Neurol 2013;70:263-266.

-2 Goadsby PJ, Silberstein SD: Migraine triggers: harnessing the messages of clinical practice. Neurology 2013;80:424-425.

-3 Hougaard A, Amin F, Hauge AW, Ashina M, Olesen J: Provocation of migraine with aura using natural trigger factors. Neurology 2013; 80:428-431.

\section{KARGER}

E-Mail karger@karger.com

www.karger.com/ene
(C) 2013 S. Karger AG, Basel

0014-3022/13/0712-0075\$38.00/0
Nitin K. Sethi, MD

Comprehensive Epilepsy Center

New York-Presbyterian Hospital, Weill Cornell Medical Center

525 East, 68th Street, New York, NY 10065 (USA)

E-Mail sethinitinmd@ hotmail.com 